\title{
Minimally Invasive Thymoma
}

National Cancer Institute

\section{Source}

National Cancer Institute. Minimally Invasive Thymoma. NCI Thesaurus. Code C45699.

A thymoma that focally infiltrates the surrounding capsule and invades the mediastinal

fat. This type of thymoma is usually recognized only after microscopic examination.

Grossly, it appears indistinguishable from encapsulated thymoma. 